\title{
To evaluate the efficacy of vaginal hysterectomy over abdominal hysterectomy among women with benign gynaecological diseases - a retrospective cohort study
}

\author{
Dulal Chandra Haldar, Suresh C Mondal, Soham C \\ Corresponding author: Dr. Suresh C Mondal, MD, Assistant Professor, Obstetrics and \\ Gynaecology, Malda Medical College and Hospital, India; Email : sureshmondal177@yahoo.com
}

Distributed under Attribution-Non Commercial - Share Alike 4.0 International (CC BY-NC-SA 4.0)

\begin{abstract}
Objectives: This study was conducted to compare non-descent vaginal hysterectomy and abdominal hysterectomy with reference to, duration of operation, postoperative complications and postoperative ambulation. Methods: This is a retrospective cohort study for a period of two years April 2017 to March 2019 among 60 patients with uterine size of 14 weeks gestation who underwent vaginal (group V) and abdominal hysterectomy (group A). Data about preoperative, operative intervention as primary outcome variables and postoperative complications as secondary outcome variables was taken from hospital records. Frequency and proportions were calculated for quantitative variables and $t$ test was used for comparison of categorical variables. Results: A total of 60 cases were selected and matched for age and parity. After statistical analysis with the collected data, it was seen that in group V operating time, blood loss, hospital stay, ambulation was found less and statistically significant ( $\mathrm{p}$ value $<0.05$ ) as compared to group A. The values are: mean operating time (94.4 vs 132.5 minutes), preoperative blood loss (201.17 vs $299.34 \mathrm{ml})$, hospital stay (5.87 vs 8.6 days), early ambulance (1.53 vs 2.5 days), early resume of sexual activities (39.9 vs 69.53 days). Conclusion: Non decent vaginal hysterectomy is a better alternative to abdominal hysterectomy in cases with uterine size $<14$ weeks.
\end{abstract}

Keywords: Hysterectomy, vaginal hysterectomy, abdominal hysterectomy, fibroid uterus, adenomyosis.

A substantial number of women undergo hysterectomy annually, and $70 \%$ of hysterectomies are performed for benign indications, including leiomyoma, adenomyosis, severe dysmenorrhea and uterine prolapse ${ }^{1}$. The surgical approach of hysterectomy is the most important factor responsible for postoperative morbidity. Vaginal, abdominal, laparoscopic and robotic assisted laparoscopic hysterectomy was the most common approaches used till date. Vaginal hysterectomy is always feasible as it has a shorter duration of hospital stay, speedier recuperation, fewer unspecified infections or febrile episodes when compared to abdominal hysterectomy ${ }^{2}, 3$. However, despite proven safety and effectiveness, vaginal hysterectomy, which is commonly utilized to treat uterine prolapse, remains underutilized for the surgical treatment of no prolapse conditions ${ }^{4}$.

Inspite of these advantages of vaginal hysterectomies, abdominal hysterectomies are being done more frequently in benign uterine conditions in India. Even in the United States, abdominal hysterectomy is commoner operation than a vaginal hysterectomy ( $66 \%$ vs $22 \%$ ) - where laparoscopic hysterectomy is done only in $12 \%$ of cases ${ }^{5}$. Previously, $75 \%$ of these procedures were performed abdominally by surgeons, despite of having a higher incidence of complication, a longer duration of hospital stay and convalescence and increased hospital charges ${ }^{6}$. Currently, there are no formal practice guidelines that clearly identify

Received: $24^{\text {th }}$ September 2020, Peer review completed: $25^{\text {th }}$ February 2021, Accepted: $3^{\text {rd }}$ March 2021. Haldar DC, Mondal SC, Soham C. To evaluate the efficacy of vaginal hysterectomy over abdominal hysterectomy among women with benign gynaecological diseases - a retrospective cohort study. The New Indian Journal of OBGYN. 2022; 8(2): 214 - 19. 
appropriate candidates for vaginal hysterectomy, abdominal hysterectomy and laparoscopically assisted vaginal hysterectomy. Lack of training and experience in vaginal and laparoscopic techniques and reluctance to perform vaginal surgery when the uterus is significantly enlarged in nulliparous women, or in the absence of uterine prolapse is a major drawback from surgeons ${ }^{7}$. Though non descent vaginal hysterectomy is said to be better than andominal hysterectomy, there are some technical difficulties when the uterus is larger in size and irregular in shape, when uterine mobility is restricted, and bilateral salpingo-oophorectomy (BSO) is required to be done in the same sitting. These factors are cited more frequently as causes of opting abdominal route.

Protagonists of abdominal hysterectomy always give importance on these factors, which prevented them from preferring vaginal hysterectomy in the non decent uterus. They are often not convinced that these factors can be overcome. Very few prospective studies are published even in global medical literature. To throw light on Indian patient's clinical characteristics, indications for non descent vaginal hysterectomy (NDVH) and abdominal hysterectomy $(\mathrm{AH})$, studies before and after AH and NDVH have never been done and never been compared, which is of paramount significance in determining indication for the route of hysterectomy and also in determining vault hematomas so that early interventions can reduce febrile morbidity. With these backgrounds the present study aimed to compare the efficacy of NDVH over abdominal hysterectomy with the objective of blood loss, operative time, hospital stay, postoperative complications per - operative technical difficulties and above all the patient satisfaction, when operated in similar cases of benign uterine pathology with non-descent uterus up to 14 weeks gestation size.

Aims and objectives -

- The aim of the study was to evaluate the efficacy of vaginal hysterectomy $(\mathrm{VH})$ over $\mathrm{AH}$ among women with benign gynaecological diseases.

- The objectives of the study were to compare and assess various factors like operative duration of surgery, intraoperative blood loss, intraoperative and postoperative complications, postoperative ambulation and duration of postoperative hospital stay and patient satisfaction.

\section{Methodology}

This retrospective cohort study was conducted in department of obstetrics and gynaecology, NRSMCH,
Kolkata during the period of April 2017 to March 2019. The target population is patients who were candidate for hysterectomy due to presence of benign aetiologies. The study was conducted on 60 female patients aged 18-70years. The subjects were matched for age and parity. 30 patients admitted for planned abdominal hysterectomy were taken as group " $\mathrm{A}$ " and 30 patients admitted for planned for non descent vaginal hysterectomy were taken for group "V" after fulfilling the inclusion and exclusion criteria's. For the better convenience of the study, study subject was selected by purposive sampling technique.

Inclusion criteria: group $\mathrm{V}$ - cases of vaginal hysterectomy in benign uterine condition like dysfunctional uterine bleeding (DUB), adenomyosis, fibroid with uterine size up to 14 weeks without descent and uterine size less than 14 weeks and with some uterine mobility. Group A cases of abdominal hysterectomy in benign uterine conditions with uterine size up to 14 weeks and without descent and history of previous vaginal birth.

Exclusion criteria: group V - cases of hysterectomy in malignant uterine and ovarian conditions, uterine size more than 14 weeks with completely restricted mobility, hysterectomy in uterine pathology with severe adhesions like chronic pelvic inflammatory disease (PID), complex adnexal mass, severe endometriosis leading to frozen pelvis and cases with gross abnormalities in size and shape of the pelvis by clinical examination. Group A - cases of hysterectomy in malignant uterine and ovarian conditions and history of previous abdominal surgery (including caesarean section) more than 1 .

Parameters studied: Time taken for surgery, the amount of blood loss, time taken for ambulation, postoperative bladder symptom (frequency, urgency), postoperative bowel symptom (constipation), time taken for discharge, time taken for sexual activities, time taken for normal day to day activity, residual vaginal length measurement at post operative visit at 4 weeks.

Study tools were hospital records and patient hospital proforma. Patients fulfilling the inclusion and exclusion criteria are selected and recruited for study, Ethical approval was taken from hospital committee. All clinical and operative observations were done by single persons (post graduate student). Information gathered was transferred through hard copy to proforma and was fed to the computer.

Data analysis: All quantitative variables were checked for normal distribution within each category of explanatory variable by using visual inspection of histograms and normality Q-Q plots. Shapiro- Wilk test was also conducted 
The New Indian Journal of OBGYN. 2021 (January-June);8(2)

to assess normal distribution and a $\mathrm{p}$ value of $<0.05$ was considered as significant. Categorical outcomes were compared between study groups using unpaired $\mathrm{t}$ test. $\mathrm{P}$ value $<0.05$ was considered statistically significant. IBM SPSS was used for statistical analysis ${ }^{8}$.

\section{Results}

A total of 60 patients in the study were divided into two groups. 30 cases in each group designated as group $-\mathrm{V}$ and group - A underwent non descent vaginal hysterectomy and abdominal hysterectomy respectively for uterine size less uterus beyond 12 weeks, previous pelvic surgery, null parity, presence of adnexal pathology, and in presence of suspicious pelvic adhesions or endometriosis. There are certain advantages of doing vaginal hysterectomy in non-descent uterus less than 14 weeks but more technical skills are needed. But with newer techniques like bisection, morcellation and myomectomy it has become easy to perform vaginal hysterectomy even in enlarged uterus in benign cases ${ }^{9}$.

In our study, age and parity distribution between the two

Table 1: Comparison of pre and intraoperative parameter between study groups $(\mathrm{N}=60)$

\begin{tabular}{|c|c|c|c|}
\hline \multirow{2}{*}{ Parameters } & \multicolumn{2}{|c|}{ Groups } & \multirow{2}{*}{$\begin{array}{l}P \\
\text { value }\end{array}$} \\
\hline & Group V $(\mathrm{N}=30)$ & Group A $(\mathbf{N}=30)$ & \\
\hline Age & $41.83 \pm 6.924$ & $43.36 \pm 7.761$ & 0.422 \\
\hline Time taken for surgery (in minutes) & $64.03 \pm 1.665$ & $93.6 \pm 0.855$ & $<0.0001$ \\
\hline The amount of estimated blood loss (in $\mathrm{ml}$ ) & $210.17 \pm 12.45$ & $299.34 \pm 14.16$ & $<0.0001$ \\
\hline Time taken for ambulance (in days) & $1.53 \pm 0.092$ & $2.53 \pm 0.092$ & $<0.0001$ \\
\hline Residual vaginal length (in $\mathrm{cm}$ ) & $6 \pm 0.1269$ & $6.56 \pm 0.1143$ & $<0.0016$ \\
\hline Time taken for discharge (in days) & $5.8 \pm 0.09$ & $8.6 \pm 0.13$ & $<0.0001$ \\
\hline Time taken for resume normal day to day activity (in days) & $33.14 \pm 3.14$ & $80.27 \pm 1.15$ & $<0.0001$ \\
\hline
\end{tabular}

than 14 weeks. Age and parity were matched in the comparative retrospective study. After statistical analysis with the collected data, it was seen that in non descent vaginal hysterectomy group $\mathrm{V}$, there was less mean operating time. Table 1 shows ( 94.4 vs 132.5 minutes), less preoperative blood loss (201.17 vs $299.34 \mathrm{ml})$, less hospital stay (5.87 vs 8.6 days), early ambulance (1.53 vs 2.5 days), early resumption of sexual activities (39.9 vs 69.53 days) and table 2 shows less postoperative complications etc. compared to abdominal group A. All the parameters were statically significant ( $p$ value $<0.05$ ) It was concluded that the vaginal approach is better in most benign conditions of uterus sized less than 14 weeks requiring hysterectomy and is more advantageous than the abdominal route with respect to recovery and complication rates.

Table 2: Comparison of postoperative parameter between study groups $(\mathrm{N}=60)$.

\begin{tabular}{llll}
\hline \multirow{2}{*}{ Parameters } & \multicolumn{2}{c}{ Groups } & P \\
\cline { 2 - 3 } & $\begin{array}{l}\text { Group V } \\
\text { (N=30) }\end{array}$ & $\begin{array}{l}\text { Group A } \\
\text { value }\end{array}$ \\
\hline Postoperative bowel symptoms & & \\
Present & $8(26.6 \%)$ & $18(60 \%)$ & \\
Occasional & $2(6.66 \%)$ & $3(10 \%)$ & 0.016 \\
Nil & $20(66.66 \%)$ & $9(30 \%)$ & \\
\hline \multicolumn{2}{l}{ Postoperative bladder symptoms } & & \\
Present & $6(20 \%)$ & $1(3.3 \%)$ & 0.031 \\
Occasional & $13(43.3 \%)$ & $9(30 \%)$ & \\
Nil & $11(36.6 \%)$ & $20(66.6 \%)$ & \\
\hline
\end{tabular}

\section{Discussion}

The common limitations for vaginal hysterectomy include absence of uterine prolapse, increase in the size of groups were comparable. The mean time taken for surgery (in minutes) for the group of non descent vaginal hysterectomy (group V) was 64.3 minutes and group of abdominal hysterectomy (group A) was 93.6 minutes. The unpaired " $t$ " test shows that there was statistically significant difference between the two groups. This finding was in comparison with Dewan Rupali et al in their study in the year 2004 that non descent vaginal hysterectomy required only 54.5 minutes ${ }^{10}$. In another study by Raju et al in the year 2014, it was seen that only 37.28 minutes required for the $\mathrm{NDVH}^{11}$. The mean operating time was 62.6 minutes for $\mathrm{NDVH}$, as described by Ray A et al in their study ${ }^{9}$. Adam Magos et al in 1996 and Octacillio Figueiredo et al in 1999 showed in their similar study that the mean operating time for their operation were 84.30 minutes and 51.00 minutes respectively ${ }^{12,13}$. The mean operating time described by $\mathrm{S}$ Bharatnur in 2010, for abdominal hysterectomy was 101 minute and that for vaginal hysterectomy was 65 minutes ${ }^{14}$. CREST study conducted by CDC between September, 1978 and August, 1981, 1,851 women from nine institutions were included in the study. In 1982 publication reported that operating time was $50 \%$ longer in abdominal.

For the amount of estimated blood loss during operation, it was $210.17 \mathrm{ml}$ for group $\mathrm{V}$ and $299.34 \mathrm{ml}$ for group A. They were statistically matched. Ray A et al ${ }^{9}$ showed (2011) in their study that the mean perioperative blood loss in $\mathrm{NDVH}$ in uterine size less than 12 weeks was only $102 \mathrm{ml}$ and $152 \mathrm{ml}$ with uterine size more than 12 weeks size. S Bharatnur in 2010 showed in his study that mean blood loss 
in abdominal hysterectomy group and NDVH group were $500 \mathrm{ml}$ and $316.4 \mathrm{ml}$ respectively ${ }^{14}$. Costa Amorim et al and Miskry $\mathrm{T}$ et al in 2003 described in their study that mean blood loss were $520 \mathrm{ml}$ and $431 \mathrm{ml}$ in NDVH group respectively ${ }^{12,15}$. In 1982 publication of CREST study reported that blood transfusion was two times greater in abdominal.

Time taken for ambulance in our study was 1.53 days in group V, while group A had 2.53 days. Results of unpaired " $t$ " test suggested that both groups had statistically significant difference $(\mathrm{p}<0.0001)$. Group $\mathrm{V}$ had a mean time taken for discharge of 5.87 days and group A had 8.6 days in our study. The unpaired " $t$ " test shows that there was statistically significant difference between the two groups. Miskry $T$ et al ${ }^{13}$ in 2003 described in their study that hospital stay in days for abdominal hysterectomy group and vaginal hysterectomy group were 7.7 days, 9.3 days and 3.6 days, 5 days respectively. $\mathrm{S}$ Bharatnur ${ }^{14}$ showed in his study that mean hospital stay in days in abdominal hysterectomy group and NDVH group were 11.1 and 9.6 days respectively. Bhadra $\mathrm{B}$ et al had experience of only 3 days mean hospital stay in NDVH ${ }^{16}$. S Taylor, R Rogers ${ }^{17}$ and co-workers compared intraoperative and postoperative complications of TAH for the enlarged, myomatous uterus with vaginal hysterectomy with morcellation. They also concluded that uterine morcellation at the time of $\mathrm{VH}$ facilitates the removal of moderately enlarged uteri and is associated with decreased hospital stay and postoperative morbidity compared to the abdominal route. Robert Kovac et al ${ }^{18}$ showed in their study that length of stay was longer after abdominal hysterectomies than laparoscopically assisted vaginal hysterectomies or vaginal hysterectomies (3.99 6 1.16 days, $2.456 \quad 1.58$ days, and $2.76 \quad 6 \quad 0.94$ days, respectively; $\mathrm{p}<0.001)$. Abha Singh et al ${ }^{19}$ concluded in their study that there was shorter hospital stay (3.62 vs. 8.18 days) in vaginal hysterectomy group.

For the time taken for resuming normal day to day activity, it was $33.14 \pm 3.14$ days for group $\mathrm{V}$ and $80.27 \pm$ 1.15 days for group A. They were statistically matched, as shown in our study. CREST study report in the year 1982 suggested that vaginal hysterectomy was associated with more unintended major surgical procedures but less febrile morbidity, bleeding requiring transfusion, hospitalization, and convalescence than abdominal hysterectomy. And the study concluded VH with prophylactic antibiotics should be strongly considered for those women of reproductive age for whom either surgical approach is clinically appropriate.
Our study also had findings that group $\mathrm{V}$ had a mean residual vaginal length at 4th postoperative visit of $6 \mathrm{~cm}$ and group A had $6.56 \mathrm{~cm}$. The unpaired " $\mathrm{t}$ " test shows that there was statistically significant difference between the two groups. The time taken to resume sexual activities was 39.9 days for group $\mathrm{V}$ and 69.53 days for group A. They were statistically matched.

Postoperative bowel symptoms for group V and group A determined by unpaired "t" test suggested that both groups had no statistically significant difference in presence of occasional bowel symptoms postoperatively. No postoperative bowel complications noted by Bhadra B et al ${ }^{16}$ in their study in 2011. Postoperative bladder symptoms for group $\mathrm{V}$ and group $\mathrm{A}$ determined by statistical analysis suggested that both groups had no statistically significant difference in presence of occasional bladder symptoms postoperatively. 12 cases out of 158 number of cases of vaginal hysterectomies had postoperative urinary tract infections, as shown by Bhadra B et al in their study ${ }^{16}$. CREST study report in the year 1982 suggested that over all complication rate of 24.5 and 42.8 per 100 women for $\mathrm{VH}$ and abdominal hysterectomy respectively and risk of having complication is 1.7 times more in abdominal group. There was a higher risk of one or more complications after abdominal hysterectomies $(9.3 \%)$ than after laparoscopically assisted vaginal hysterectomies $(3.6 \%$; $<0.001)$ or vaginal hysterectomies $(5.3 \% ; \mathrm{p}<0.001)$, as stated by Robert Kovac et al ${ }^{18}$ in their study. Lakeman MM et al ${ }^{20}$ described in their study that no differences were observed in the prevalence of micturition symptoms between patients who underwent vaginal and abdominal hysterectomy perioperatively. But 10 years after vaginal hysterectomy, significantly more women had been treated for mitcturiion symptoms (18 versus $8 \%$; $\mathrm{P}=0.02$; adjusted OR 3.8, 95\% CI 1.2-11.6). Defecation symptoms also seemed more common after vaginal hysterectomy (58 versus $46 \% ; \mathrm{P}=0.08$ ), but this was not statistically significant. Chandrakar $\mathrm{K}$ et al ${ }^{21}$ showed in their study that postoperative complications are more in abdominal hysterectomy like fever, infection, ureter injuries.

Limitation: As the study was retrospective and the data was collected from records the study did not compare early postoperative complications like fever, urinary tract infection (UTI), respiratory tract infections, vault sepsis and haematoma formation. There was no clear demographic data on patient's education, background, socio-economic status, number of children etc. post operative complications like fistula and dyspareunia were also not recorded. Though the study was retrospective in nature but suggested $\mathrm{VH}$ a safe 
procedure and moreover it was a single hospital based study. Large randomized controlled trials should be performed to identify differences in $\mathrm{VH}$ and $\mathrm{LH}$ covering different geographical areas.

\section{Conclusion}

The study concluded that non descent vaginal hysterectomies (without uterine prolapse) for the treatment of benign disease in less than 14 weeks sized uterus had certain advantages in relation to abdominal hysterectomy in same indications. Less operative time, less intraoperative blood loss, less hospital stays, early recovery and ambulance with early discharge from hospital, low postoperative complications demonstrate that the vaginal route should be the choice of hysterectomy operation for non descent cases. Moreover, good residual length of vagina and early resume of sexual activity postoperatively are other advantages of NDVH.

\section{Conflict of interest: None. Disclaimer: Nil.}

\section{References}

1. Whiteman MK, Hillis SD, Jamieson DJ, Morrow B, Podgornik MN, Brett KM, et al. Inpatient hysterectomy surveillance in the United States, 2000-2004. Am J Obstet Gynecol. 2008;198(1):34.e1-34.e7.

2. Nieboer TE, Johnson N, Lethaby A, Tavender E, Curr E, Garry R, et al. Surgical approach to hysterectomy for benign gynaecological disease. Cochrane Database Syst Rev. 2009;(3):CD003677.

3. Dewan P, Gupta P. Burden of Congenital Rubella Syndrome (CRS) in India: a systematic review. Indian Pediatr. 2012;49(5):377- 99.

4. Moen MD, Richter HE. Vaginal hysterectomy: Past, present, and future. Int Urogynecol J Pelvic Floor Dysfunct. 2014;25(9):1161-5.

5. Wu JM, Wechter ME, Geller EJ, Nguyen T V., Visco AG. Hysterectomy rates in the United States, 2003. Obstet Gynecol. 2007;110(5):1091-5.

6. Weber AM, Lee JC. Use of alternative techniques of hysterectomy in Ohio, 1988-1994. N Engl J Med. 1996;335(7):483-9.

7. Mehta K, Prakash O, Fatehpuriya DS, Verma L. Comparative study of abdominal hysterectomy and vaginal hysterectomy in non descent cases a prospective study. Int J Reprod Contraception, Obstet Gynecol. 2017; 6(4):1265.

8. IBM Corp. Released 2013. IBM SPSS Statistics for Windows, Version 22.0. Armonk, NY: IBM Corp.
9. Ray A, Pant L, Balsara R, Chaudhury R. Non descent vaginal hysterectomy: A constantly improving surgical art. J Obstet Gynecol India. 2011;61(2):182-8.

10. Dewan R, Agarwal S, Minocha B SS. Non- descent Vaginal Hysterectomy - An Experience. J Obs Gynecol Ind. 2004;54(4):376-8.

11. Raju VS, Girija BS. Comparison of vaginal hysterectomy for non descent uterus with abdominal hysterectomy. Indian J Public Heal Res Dev. 2014;5(1):15-8.

12. Figueiredo Netto O. Vaginal removal of the benign nonprolapsed uterus: experience with 300 consecutive operations. Obstet Gynecol. 1999; 94(3): 348-51.

13. Miskry T, Magos A. Randomized, prospective, doubleblind comparison of abdominal and vaginal hysterectomy in women without uterovaginal prolapse. Acta Obstet Gynecol Scand. 2003;82(4):351-8.

14. Bharatnur S. Comparative study of abdominal versus vaginal hysterec tomy in non descent cases. Internet $\mathrm{J}$ Gynecol Obstet. 2011;15(2): 1528.

15. Costa AAR, Amorim MMR de, Cursino $T$. Histerectomia vaginal versus histerectomia abdominal em mulheres sem prolapso genital, em maternidadeescola do Recife: ensaio clínico randomizado. Rev Bras Ginecol e Obs. 2003;25(3):169-76.

16. Bhadra B, Choudhury AP, Tolasaria A. Non Descent Vaginal Hysterectomy ( NDVH ): Personal Experience in 158 Cases. Al Ameen J Med Sci. 2011; 4: 23-7.

17. Taylor S, Romero A, Qualls C RR. Abdominal hysterectomy for the enlarged myomatous uterus compared with vaginal hysterectomy with morcellation. Am Journals Obstet Gynaecol. 1996; 162: 994-8.

18. Kovac SR. Vaginal hysterectomy. Baillieres Clin Obstet Gynaecol. 1997; 11(1): 95-110.

19. Abha Singh SB. Vaginal hysterectomy for non prolapsed uterus. J Obs Gynaecol India. 2006;56(2):152-5.

20. Lakeman M, Van Der Vaart CH, Roovers J. A long-term prospective study to compare the effects of vaginal and abdominal hysterectomy on micturition and defecation. BJOG An Int J Obstet Gynaecol. 2011;118(12):1511-7.

21. Chandrakar DK, Singh DN, Charla DS. Comparative study on non descent vaginal hysterectomy verses abdominal hysterectomy for benign uterine conditions. Int J Med Res Rev. 2016;4(11):2071-6. 
The New Indian Journal of OBGYN. 2021 (January-June);8(2)

Dulal Chandra Haldar ${ }^{1}$, Suresh C Mondal ${ }^{2}$, Soham $\mathrm{C}^{3}$ ${ }^{1}$ Demonstrator, Department of Obstetrics and Gynaecology, Calcutta National Medical college and Hospital, Kolkata, India; ${ }^{2}$ Assistant Professor,
Obstetrics and Gynaecology, Malda Medical College and Hospital, India; ${ }^{3}$ R.M.O, Obstetrics and Gynaecology, Malda Medical College and Hospital, India. 